\title{
Intra-accumbal and Peripheral administration of nicotine reduces the side-effects of Inescapable Stress
}

\author{
Hamid Reza Malayeri ${ }^{1}$, Hedayat Sahraei ${ }^{2}$, Hengameh Alibeik ${ }^{1}$, Boshra Hatef ${ }^{2}$, Gholam Hossein Meftahi ${ }^{2}$, \\ Alireza Mohammadi ${ }^{2} *$ \\ ${ }^{1}$ Department of Biology, School of Biological Sciences, Islamic Azad University, North Tehran Branch, Tehran, Iran. \\ ${ }^{2}$ Neuroscience Research Center, Baqiyatallah University of Medical Sciences, Tehran, Iran.
}

\section{ARTICLE INFO}

Article history:

Received on: 02/06/2017

Accepted on: 08/11/2017

Available online: 30/12/2017

Key words:

Stress, Nucleus accumbens, Mesolimbic, Nicotine,

Anorexia.

\begin{abstract}
Background: The mesolimbic dopaminergic system plays an important role in controlling the effects of stress. Here, the role of nicotinic receptors in the nucleus accumbens, one of the most important parts of the mesolimbic system in reducing the effects of stress in mice has been studied.

Methods: Bilateral intra-accumbal (shell of nucleus accumbens; sNA) cannulation was performed carefully. Animals were allocated randomly into nine groups and received nicotine intra-peritoneally (IP; $0.25, .05$, and 1 $\mathrm{ml} / \mathrm{Kg}$ ) and intra-accumbally (sNA; 1,5 and $10 \mu \mathrm{g} /$ mouse), respectively. 30 minutes later saline and nicotine injection, the animal received an electric shock stress from the soles of the feet for 60 seconds. The body, brain and adrenal glands weight, food and water consumption and anorexia time were evaluated.

Results: The results showed that IP administration of $1 \mathrm{mg} / \mathrm{Kg}$ nicotine (IP Nic 1) and intra-accumbal injection of 1 and $5 \mu \mathrm{g}$ /mouse nicotine (NAc Nic 1 and 5) lead to weight loss. Although, intra-sNA injection of nicotine couldn't improve the food consumption, but the significant increases in food intake were observed in the IP Nic 1. The water intake increased and the brain weight decreased dose-dependently by rises of nicotine dose. The weight of the adrenal gland was significantly raised in IP Nic groups. Anorexia (decreased appetite), decreased or increased depending on the nicotine dose.
\end{abstract}

Conclusion: We conclude that intra-accumbal nicotine administration reduces the signs of stress in a dose dependent manner, which probably is associated with the role of nicotinic acetylcholine receptors.

\section{INTRODUCTION}

Stress is a reaction alongside a perceived threat (real or imaginary) to physical, mental, emotional and spiritual health, leading to a series of physiological responses and adaptations. In other words, any environmental or mental factors that make life difficult to animate can be considered as stress and stimulant that disturbs homeostasis of the body, called stressor (Tilbrook et al., 2000; Dalooei et al., 2016).

The activation of the Hypothalamic-Pituitary-Adrenal axis (HPA axis) and increasing the level of Adrenocorticotropic hormone

\section{* Corresponding Author}

Alireza Mohammadi, Neuroscience Research Center, Baqiyatallah University of Medical Sciences, P.O.Box: 19395-6558, Tehran, Iran. Email:ar.mohammadi_@bmsu.ac.ir,Phone:+98 (21)26127281
(ACTH) level, is one of the homeostatic mechanisms observed in all types of stress in laboratory animals (Ailing et al., 2008). The longstanding release of stress hormones raises the risk of metabolic and neuropsychiatric disorders such as diabetes, anxiety, depression, and schizophrenia (Mohammadi et al., 2017). Thus, understanding the mechanisms implicated in brain responses to stress is the most important key to inhibit stress and its side effects. Studies have shown that the NAc (a part of the ventral striatum), Plays a vital role in reward, reinforcement and motivational aspects of behaviors toward addiction. This nucleus is involved in reward aspects of the addictive substance, psychological dependence, and withdrawal syndromes. The core and shell of NAc (cNAc, sNAc), have different functions. Addictive drugs increase dopamine release in the sNAc. 
Dopamine is the most studied neurotransmitter and play a crucial role in the pathophysiology of neuropsychiatric disorders such as anxiety, depression, and schizophrenia (Javadpour and Mohammadi, 2015; Noori-Daloii et al., 2015; Javadpour and Mohammadi, 2016). It has been suggested that the sNAc may be related to stimulus-reward associations which can be changed by addictive drugs. The cNAc, which secretes hormones include dopamine, glutamate, and serotonin, has a critical role in models of drug-seeking behavior such as Pavlovian approach (Chiari et al., 1999; Ambroggi et al., 2011). Nicotine is an agonist of nicotinic acetylcholine receptors and is existent in the range of 2-7 $\mu \mathrm{g} / \mathrm{kg}$ of different comestible plants. By way of nicotine binds to these receptors, the intracellular cation is augmented and the cell becomes depolarized. Nicotine could cause enlarged dopamine circulation through systematic activity on ionotropic receptors of dopamine, GABA and the arrivals of glutamatergic neurons ( $\mathrm{G}$ Hunter, 2012). Nicotine is a robust base, which rapidly absorbed crossways respiratory tract, skin, and oral mucosa and spreads the brain through a vein spreading in 8 seconds (Benowitz et al., 1991). Furthermore, nicotine is the most psychoactive complexes in tobacco (BLISS and AILION, 1969; Betz, 1990; Bidzseranova et al., 1992; Blokland et al., 1999) and its pharmacological effects are due to encouraging the release of numerous neurotransmitters (Bombig et al., 2003). It has been demonstrated that smoking decreases anxiety due to nicotine withdrawal (Bon and Garthwaite, 2003). Long-lasting stimulation of the sympathetic nervous system by nicotine upsurges metabolic percentage and the uptake of brown fat and results in weight loss (Betz, 1990). Nicotine could be used to treat various diseases (Bidzseranova and Varga et al., 1992). It has been shown that acute systemic administration of nicotine improves the memory and cognitive performance (Boscarino et al., 2011). Likewise, it increases dynamic activity and food associated conditions-reflex. In this study, we evaluated the effects of peripheral and intra-accumbal injection of nicotine on metabolic and behavioral responses to inescapable stress in male NMRI mice.

\section{MATERIALS AND METHODS}

Animals

Fifty-four adult NMRI male mice (25-35 grams, the Pasteur Institute, Tehran, Iran) were used throughout the study and randomly allocated to 9 groups (6 for each group including: negative control group; control $^{-}$, without any intervention), two Positive control groups (control $\mathrm{IP}^{+}$and control $\mathrm{NAc}^{+}$, receiving $1 \mathrm{ml} / \mathrm{mouse}$ and $10 \mu \mathrm{g} /$ mouse saline, respectively), three intra-peritoneal groups (IP nic, receiving $0.25,0.5$ and 1 $\mathrm{mg} / \mathrm{kg}$ nicotine) and three intra-accumbal groups (NAc nic, getting 1,5 and $10 \mu \mathrm{g} /$ mouse nicotine). The animals were housed six per cage $\left(22 \pm 2{ }^{\circ} \mathrm{C}\right.$ with a $12 / 12 \mathrm{~h}$ light/dark cycle) with ad libitum food and water available. All experiments were done in accordance with standard ethical guidelines and were approved by the local ethical committee (Baqiyatallah University of Medical Sciences, Use and Care of Animals Committee, 87/211-2015).

\section{Drugs}

The nicotine [(-)-Nicotine ditartrate] was purchased from Tocris Bioscience (Cat. No. 3546) and dissolved in sterile saline before use and injected into the sNAc (1, 5 and $10 \mu \mathrm{g} /$ mouse) or peritoneum $(0.25,0.5$ and $1 \mathrm{mg} / \mathrm{kg})$.

\section{Stress induction}

Stress box is a Plexiglas device with 9 compartments. The Holes in each compartment and their transparent walls allow animals to communicate with each other. The floor of the device consists of stainless steel rods that connect to an electroshock device (ESD) with adjustable voltage, frequency and time.

\section{Experimental design}

After an adaptation period (seven days), animals received nicotine in experimental groups (IP Nic and NAc Nic) and saline in control ${ }^{+}$groups (control $\mathrm{IP}^{+}$and control $\mathrm{NAc}^{+}$), before stress induction. Animals were placed in stress box 20 minutes before exposure to stress. Electric foot shock (voltage of 60 volts and frequency of 10 hertz for 60 seconds) was applied to animals daily for 7 consecutive days except for two unpredictable days. After a 10-minute rest, the animals were returned to their cage and time interval between their return and the beginning of feeding was measured and declared as anorexia. Moreover, the weight of animals and water and food intake were measured. In groups undergoing surgery, experiments were started after the recovery period of 5 to 7 days.

\section{Surgical procedures}

To inoculate nicotine or saline into the nucleus accumbens, the animals were anesthetized by IP injection of ketamine $(50-75 \mathrm{mg} / \mathrm{kg}$ ) and diazepam $(5-7 \mathrm{mg} / \mathrm{kg})$. A stainless steel guide cannula (Gauge 21) was located within the sNAc (the stereotaxic coordinates were AP: $1.56 \mathrm{~mm}, \mathrm{ML}$ : +/- $0.5 \mathrm{~mm}$, DV: $7 \mathrm{~mm}$ from bregma, Fig1).

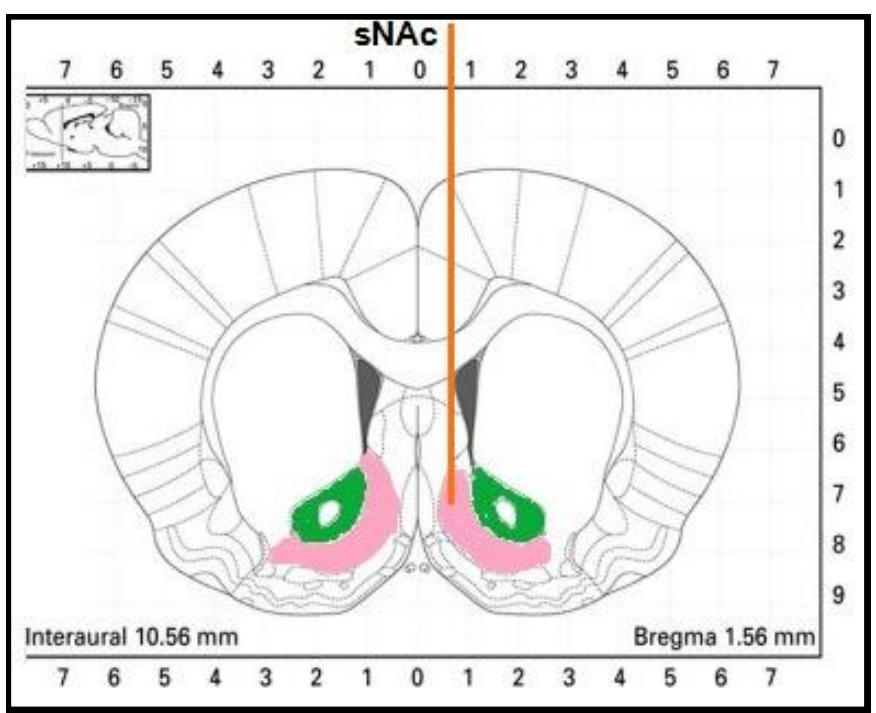

Fig. 1: Location of the guide cannula in the sNAc (green: core and ink: shell). 
Inoculation into the sNAc was achieved by a stainless steel injection cannula (Gauge 30) which was connected to a $5 \mu \mathrm{L}$ Hamilton syringe by an elastic cannula. At the end of the experiments, animals were anesthetized with ketamine (100 $\mathrm{mg} / \mathrm{kg}$ ) and their adrenal glands and brains were removed, fixed using $4 \%$ formalin and their weights were determined.

\section{Data analysis}

Data were presented as mean \pm standard error of mean (SEM) and analyzed using one-way analysis of variance (Bidzseranova and Varga et al.) followed by an LSD test to analyze changes in the brain's and the adrenal gland's weight and Repeated Measures ANOVA to analyze changes in body weight, water and food intake. $\mathrm{P}<0.05$ was measured as an indication of a significant difference. In all data analysis, when the statistically significant difference was $0.05(\mathrm{P}<0.05)$, the power analysis was among 0.6 to 0.64 . Also, when the statistically significant differences were 0.01 and $0.001(\mathrm{P}<0.01$ and $\mathrm{P}<0.001)$, the power analysis were among 0.7 to 0.72 and 0.81 to 0.86 , respectively. In insignificant status, the power analysis was lower than 0.08

\section{RESULTS}

Effects of IP administration of nicotine

Effects of IP administration of nicotine on body weight and food intake

Control $^{-}$and IP Nic 0.25 and $0.5 \mathrm{mg} / \mathrm{kg}$ groups showed weight gain, whereas control $\mathrm{IP}^{+}$and the IP Nic 1 groups showed weight loss (Fig2 A). The animals of control ${ }^{-}$, control $\mathrm{IP}^{+}$, and IP Nic 0.5 groups showed increased food intake. The highest increase was observed in the IP Nic 1 and the lower one was observed in the stressed group received $0.25 \mathrm{mg} / \mathrm{kg}$ nicotine (IP Nic 0.25 , $\mathrm{P}<0.0001$, Fig. 2 B).

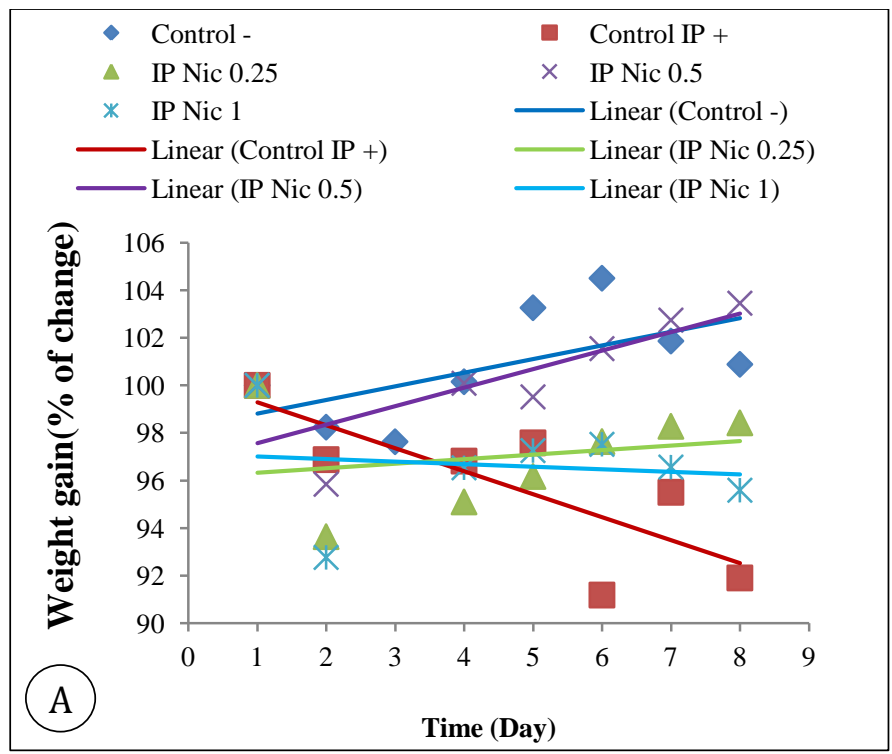

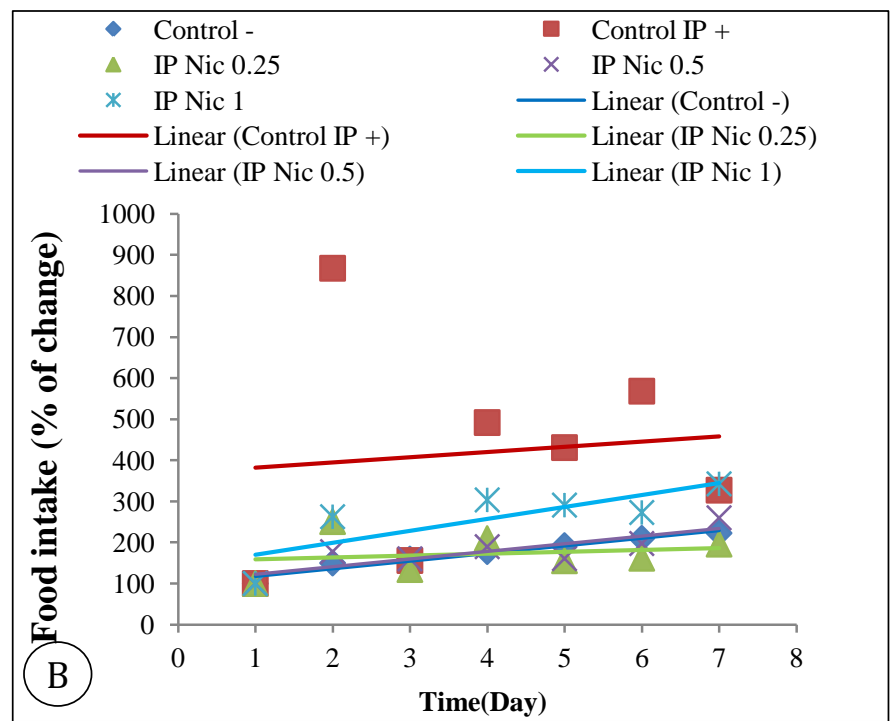

Fig. 2: The average of body weight (A) and amount of food intake (B) in mice under stress with and without nicotine injection $(\mathrm{P}<0.0001$, for food intake and weight changes).

\section{Effects of IP administration of nicotine on brain weight and water intake}

The results showed that the amount of water intake depends on the dose of nicotine and exposure to stress (Fig3 A). Water intake increased dose-dependently by rises of nicotine dose. The average brain weight in the control $\mathrm{IP}^{+}$and groups received nicotine decreased significantly compared with control group ( $\mathrm{P}$ $<0.0001$, Fig3 B).
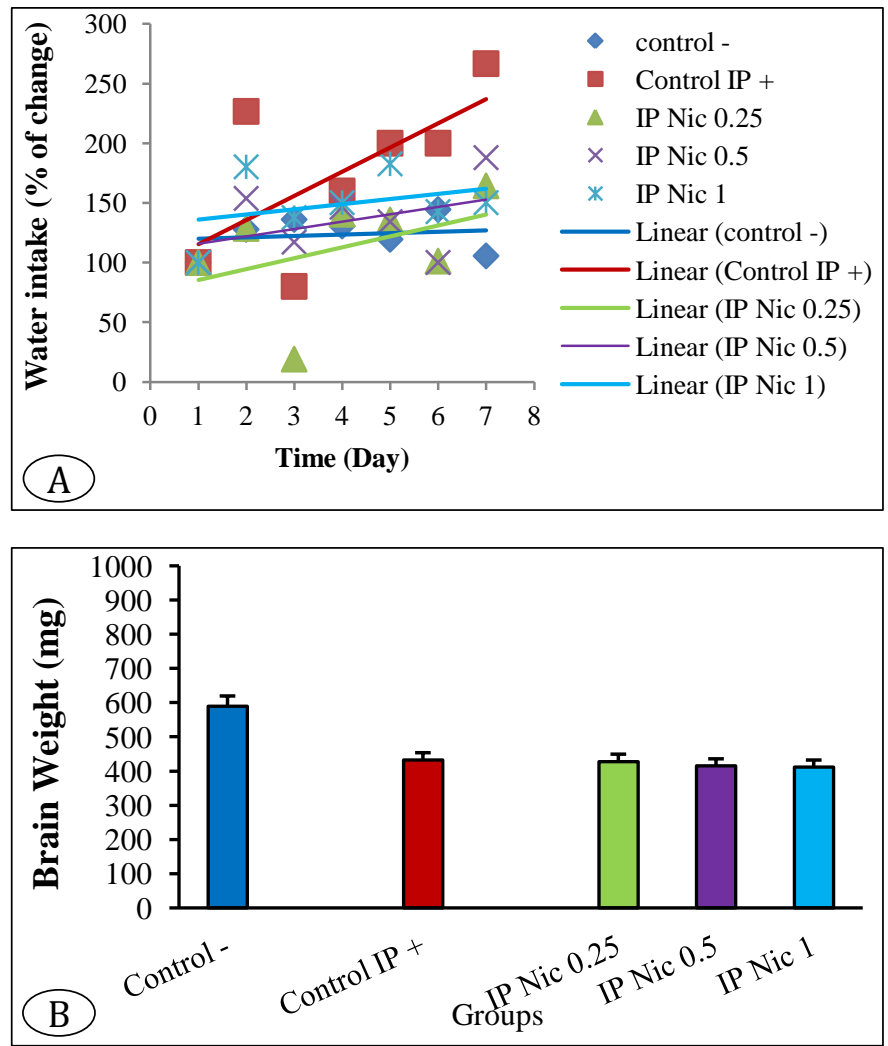

Fig. 3: The amount of water intake (A) and average brain weight (B) $(\mathrm{P}<0.0001$, for brain weight and water intake). 


\section{Effects of IP administration of nicotine on adrenal glands weight and anorexia}

The average weight of the adrenal glands in the IP group received $1 \mathrm{mg} / \mathrm{kg}$ nicotine (IP Nic 1) was significantly more than the control ${ }^{-}$group $\left(\mathrm{P}<0.05\right.$, Fig. 4A). Control $^{-}$and IP groups received $0.25 \mathrm{mg} / \mathrm{kg}$ nicotine (IP Nic 0.25) showed decreased anorexia (increased appetite, Fig. 4B). Anorexia was increased in IP groups received 0.5 and $1 \mathrm{mg} / \mathrm{kg}$ nicotine (IP Nic 0.5 and 1 ). The results showed that the appetite depends on the severity and duration of stress and the dose of nicotine.
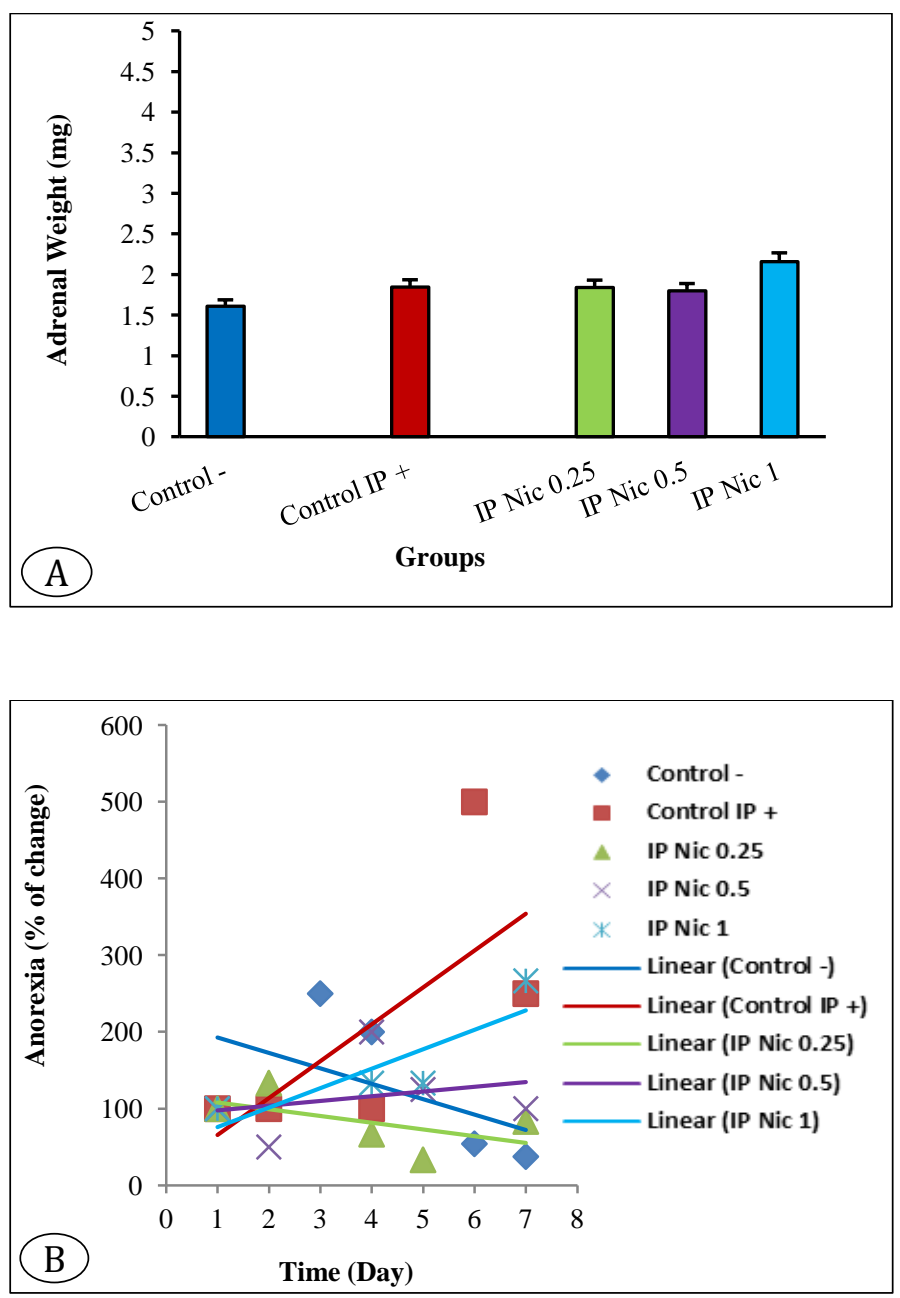

Fig. 4: The average adrenal gland weight (A) and anorexia (B) in the positive and negative control groups and stressed groups received different doses of nicotine $(\mathrm{P}<0.05$ for adrenal weight $(*)$ and $\mathrm{P}<0.0001$ for anorexia).

\section{Effects of bilateral sNA injection of nicotine}

Effects of bilateral injection of nicotine in sNA on body weight and food intake

The animals of control ${ }^{-}$, control $\mathrm{NAc}^{+}$, and sNA groups received $10 \mu \mathrm{g} /$ mouse nicotine (NAc Nic 10) showed weight gain and groups received 1 and $5 \mu \mathrm{g} /$ mouse nicotine (NAc Nic 1 and 5) presented weight loss (Fig5 A). Control $^{-}$group displayed the higher rate of food intake than other groups; on the other hand,
intra-sNA injection of nicotine couldn't improve the food consumption in mice which have been exposed to inescapable stress (Fig. 5 B). It seems that the body weight and food intake depend on the dose of nicotine and exposure to stress.
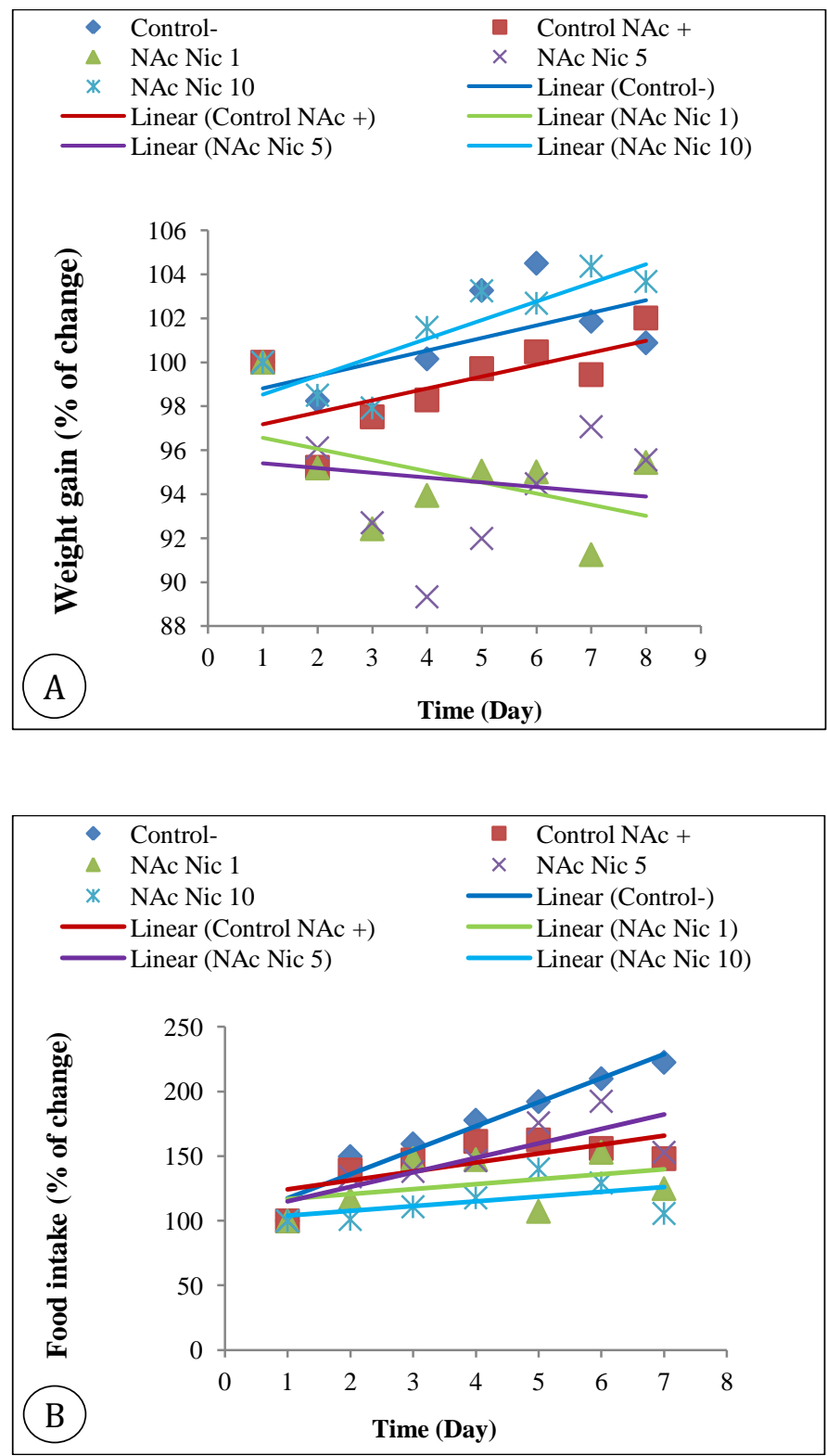

Fig. 5:The average body weight (A) and amount of food intake (B) in mice under stress with and without intra-accumbal injection of nicotine. $(\mathrm{P}<0.0001$, for weight changes and food intake).

\section{Effects of bilateral injection of nicotine in sNA on brain weight and water intake}

According to the results, the amount of water intake was increased in all groups and the lowest one was seen in control ${ }^{-}$ group (Fig6 A). An increase in the average brain of weight following bilateral injection of nicotine in the sNA in animals of 
the control $\mathrm{NAc}^{+}$group was significantly higher than control $(\mathrm{P}<0.05)$. The average of brain weight was decreased in a group with an injection of $10 \mu \mathrm{g} /$ mouse nicotine (NAc Nic 10) $(\mathrm{P}<0.05$, Fig. 6 B).
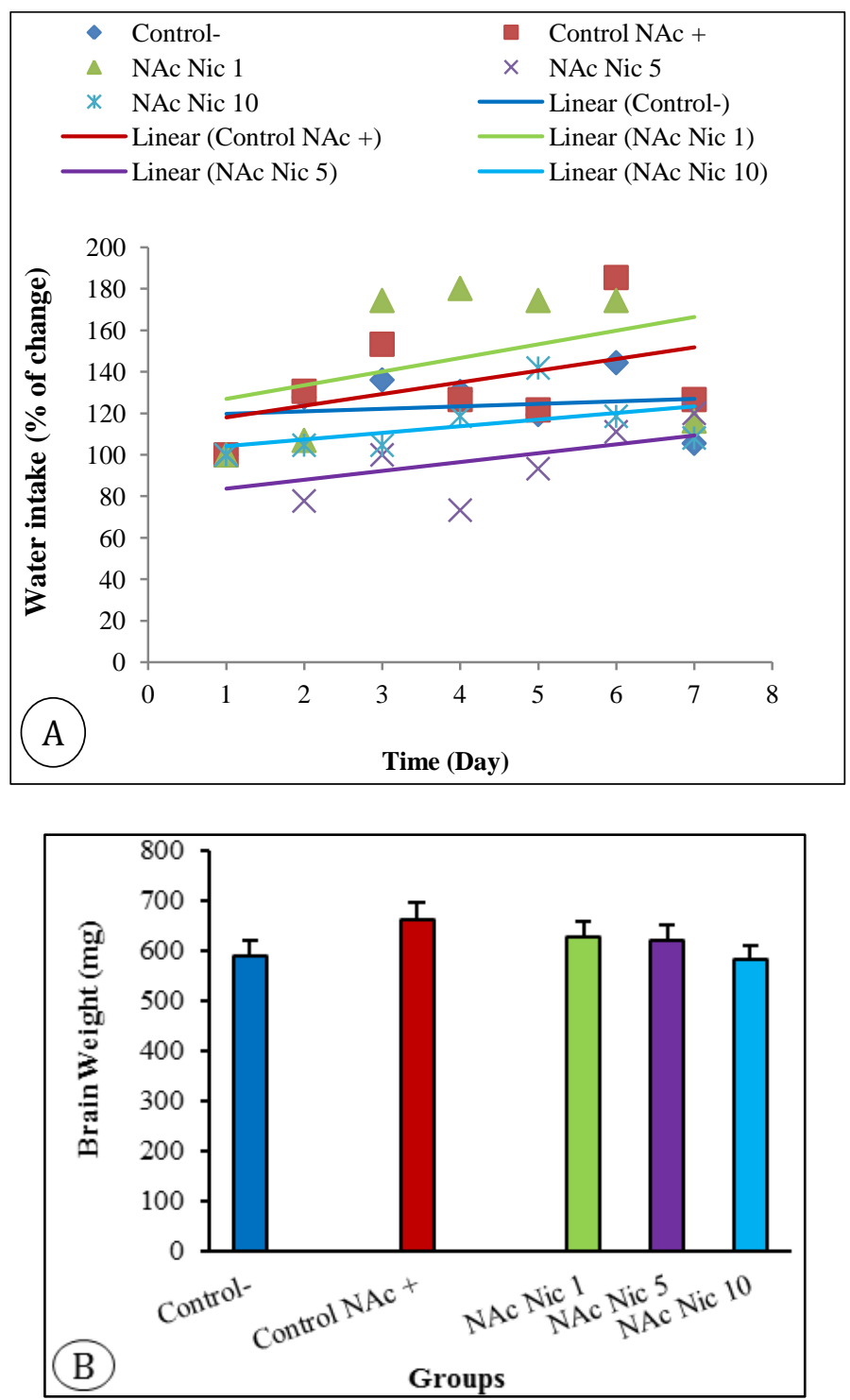

Fig. 6: The amount of water intake (A) and average brain weight (B). $(\mathrm{P}<0.0001$, for water intake and brain weight).

\section{Bilateral injection of nicotine in SNA on adrenal gland weight and anorexia}

The sNA group received $1 \mu \mathrm{g} /$ mouse nicotine (NAc Nic 1), showed a significant decrease in average weight of adrenal glands compared with the control $\mathrm{NAc}^{+}$group (Fig7 A). The stressed group (NAc Nic 1) showed more increase in anorexia (decreased appetite) than control $\mathrm{NAc}^{+}$and NAc Nic 10. The NAc Nic 5 and control ${ }^{-}$groups showed decreased anorexia (Fig7 B). The results showed that the craving to food intake depends on the dose of nicotine and whether the animals are underneath stress or not.
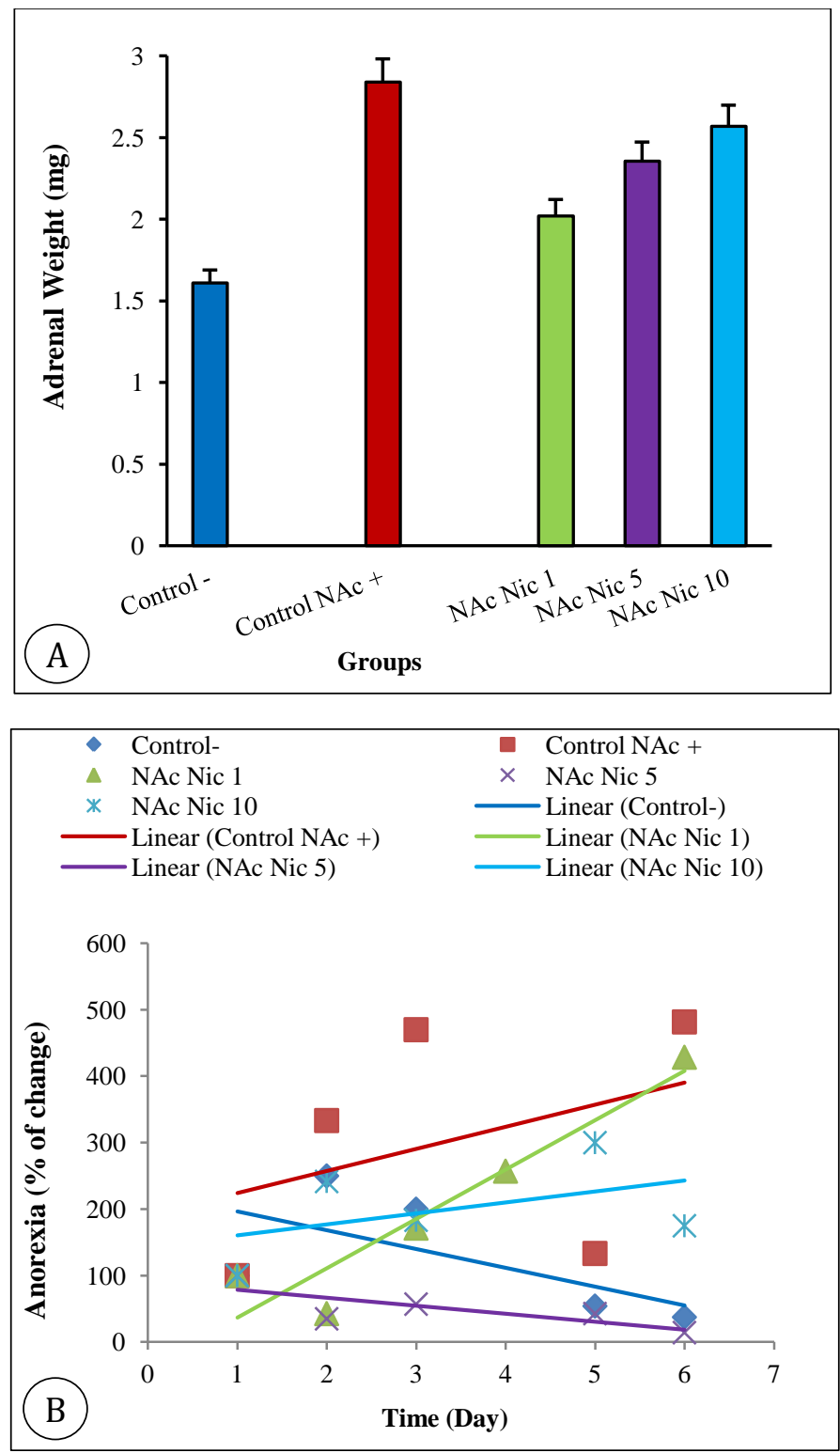

Fig. 7: The average $f$ adrenal gland weight (A) and anorexia (B) in positive and negative control groups and stressed groups received intra-hippocampal different doses of nicotine. $(\mathrm{P}<0.05(*)$ and $\mathrm{P}<0.001$ (***) for adrenal weight and $\mathrm{P}<0.0001$ for anorexia).

\section{DISCUSSION}

In the present study, we have assessed the stimulation of nicotinic acetylcholine receptors in the nucleus accumbens and its consequence on inescapable stress responses in mice. In line with previous studies, our results have shown that inescapable stress causes widespread alterations in animal performance, including reduced body weight loss, brain weight, food intake, increased anorexia and water intake and adrenal gland weight (McEwen, 2007; Colomer et al., 2010; G Hunter, 2012; Guérineau et al., 2012; Lutfy et al., 2012). It would be renowned that according to preceding studies, stress stimulates HPA axis and upsurges secretion of epinephrine and glucocorticoids from the central and cortical parts of the adrenal gland, respectively (McEwen, 2007; 
Hunter et al., 2010). It has been reported that the reduced level of dopamine in the nucleus accumbens recovers the animal's ability to acquire used to stress following inescapable stress (Dubrovsky, 2005; Viveros et al., 2007; Colomer and Olivos-Oré et al., 2010; Hunter and Bloss et al., 2010). Various parts of reward system are involved in the variation of stress responses and the nucleus accumbens as a main parts of this reward system, acting a vital role in inhibiting the effects of stress (Zhao et al., 2007). In the present study, the stimulation of nicotinic receptors in the nucleus accumbens induced different responses indicating the influence of the cholinergic system in the nucleus accumbens. Our study has expressed that inescapable stress decreases brain weight which is in agreement with other studies (McEwen, 2007). It is well known that stress reduces intracellular cytoskeleton of neurons in different parts of the brain. Research showed that the size of the amygdala and hippocampus are decreased in chronic stress, which is related to glucocorticoids secreted by the adrenal gland. In immobilization stress, the number of dendritic spines, dendrites, and synapses established in the amygdala and prefrontal cortex are decreased in rats. fMRI studies in humans have shown that the volume and size of active regions in hippocampus and amygdala are reduced in individuals with chronic stress. Numerous studies have shown the high density of glucocorticoid and mineralocorticoid receptors in different areas of the cerebral cortex, especially prefrontal cortex and different areas of the limbic system, such as hippocampus and amygdala. So impressionability of these areas of high concentration of glucocorticoid hormones in chronic stress conditions is much higher than other areas in the nervous system (McEwen, 2007). The present study has demonstrated an increase in adrenal gland weight of stressed animals. Previous investigations presented the sensitivity of both central and peripheral parts of the adrenal gland to stress stimulations. In stress conditions, activation of HPA axis and release of ACTH hormone affect adrenal gland cells, especially zona fasciculata and lead to an increase in number and size of glucocorticoid hormonesecreting cells (McEwen, 1998). On the other hand, stress can stimulate sympathetic nervous system and increase the size and activity of Chromaffin cells in the adrenal gland (Miller and O'Callaghan, 2002). Reduced feeding activity, increased water intake and subsequent weight loss has also been observed in our project which is consistent with preceding research (Müller et al., 2000; Miller and O'Callaghan, 2002; Myers and Rinaman, 2002; Amouei et al., 2016). Our analysis presented that nicotine in doses of 0.25 and $0.5 \mathrm{mg} / \mathrm{kg}$ decreased anorexia and in doses of $1 \mathrm{mg} / \mathrm{kg}$ increased it. Moreover, it has been revealed that 0.25 and 0.5 $\mathrm{mg} / \mathrm{kg}$ nicotine inhibited the effect of stress on weight loss and $1 \mathrm{mg} / \mathrm{kg}$ nicotine reinforced this effect. It means that peripheral administration of nicotine may have double effects in human and animal models as some doses causes anorexia and others have appetite stimulating effects (Le Novere and Changeux, 1995; Cao et al., 2010; Hunter and Bloss et al., 2010; Niehaus et al., 2010). It seems that the influences of nicotine in inhibiting unwanted psychological complications of stress are more important than its influences on metabolic and physical aspects of stress and this may have a role in the etiology of smoking. Leao and colleagues (2012) showed that sensitivity induced by stress reinforces drug-seeking behavior caused by nicotine and reduces the CREB protein (cAMP response element-binding protein) in nucleus accumbens, which indicate the interaction of stress and nicotine in mental performance (Leão et al., 2012). No studies to our knowledge have yet been conducted regarding the interaction between nicotine and stress in regulating brain volume. In our study stimulation of nicotinic acetylcholine receptors in the nucleus accumbens by nicotine, prevents increased brain weight caused by stress. We have also demonstrated that administration of saline into the nucleus accumbens of stressed rats causes increased brain weight, which is inconsistent with previous findings of the effect of stress on reduced size and volume of neurons in the brain (McEwen, 2007). Therefore, increased brain weight in animals receiving saline into nucleus accumbens should be considered in future studies. In our study, injection of nicotine into the nucleus accumbens reduced stress-induced adrenal gland hypertrophy in a dose-dependent manner. The effect of nicotine on the size of the adrenal glands and increased level of the glucocorticoid hormones has been proven.

\section{CONCLUSION}

Stimulation of nicotinic receptors in the nucleus accumbens may inhibit the effects of stress in a dose-dependent manner which is indicated by parameters such as weight changes in the brain and adrenal gland as well as metabolic and behavioral responses. We found that IP administration of $1 \mathrm{mg} / \mathrm{Kg}$ nicotine (IP Nic 1) and intra-accumbal injection of 1 and $5 \mu \mathrm{g} / \mathrm{mouse}$ nicotine (NAc Nic 1 and 5) lead to weight loss. Although, intrasNA injection of nicotine couldn't improve the food consumption, but the significant increases in food intake were observed in the IP Nic 1. The water intake increased and the brain weight decreased dose-dependently by rises of nicotine dose. The weight of the adrenal gland was significantly raised in IP Nic groups. Anorexia (decreased appetite), decreased or increased depending on the nicotine dose. Altogether, we conclude that intra-accumbal nicotine administration reduces the signs of stress in a dose dependent manner, which probably is associated with the role of nicotinic acetylcholine receptors. Future research with a focus on molecular and cellular changes caused by stress should be done to understand the mechanisms responsible for the inhibitory effects of nicotine on stress.

\section{ACKNOWLEDGEMENTS}

Financial support and sponsorship: This work was supported by the grant from the Neuroscience Research Center, Baqiyatallah University of Medical Sciences, Tehran, Iran.

Conflict of Interests: There are no conflicts of interest. 


\section{REFERENCES}

Ailing F, Fan L, Li S, Manji S. Role of extracellular signalregulated kinase signal transduction pathway in anxiety. J Psychiatr Res, 2008; 43: 55-63.

Ambroggi F, Ghazizadeh A, Nicola SM, Fields HL. Roles of nucleus accumbens core and shell in incentive-cue responding and behavioral inhibition. J Neurosci, 2011; 31: 6820-6830.

Amouei N, Sahraei H, Alibeik H, Meftahi GH, Bahari Z, Mohammadi A. Intrahippocampal and Peripheral Effects of Nicotine Injection on the Metabolic and Behavioral Response to Inescapable Stress. Biosci Biotechnol Res Asia, 2016; 13: 1363-1371.

Benowitz NL, Jacob P, Denaro C, Jenkins R. Stable isotope studies of nicotine kinetics and bioavailability. Clin Pharmacol Ther, 1991; 49: 270-277.

Betz H. Homology and analogy in transmembrane channel design: lessons from synaptic membrane proteins. Biochemistry, 1990; 29: 3591-3599.

Bidzseranova A, Varga J, Telegdy G. The effects of receptor blockers on brain natriuretic peptide-32-induced action on passive avoidance behavior in rats. Neuropeptides, 1992; 22: 107-110.

Bliss EL, Ailion J. Response of neurogenic amines to aggregation and strangers. J Pharm Exp Ther, 1969; 168: 258-263.

Blokland A, De Vente J, Prickaerts J, Honig W, Van Ittersum MM, Steinbusch H. Local inhibition of hippocampal nitric oxide synthase does not impair place learning in the Morris water escape task in rats. Eur J Neurosci, 1999; 11: 223-232.

Bombig MTN, Ferreira C, Mora O, Soares JD, Póvoa R, Filho $\mathrm{BL}$, et al. Pravastatin protection from cold stress in myocardium of rats. Jpn Heart J, 2003; 44: 243-255.

Bon CL, Garthwaite J. On the role of nitric oxide in hippocampal long-term potentiation. J Neurosci, 2003; 23: 1941-1948.

Boscarino JA, Erlich PM, Hoffman SN, Rukstalis M, Stewart WF. Association of FKBP5, COMT and CHRNA5 polymorphisms with PTSD among outpatients at risk for PTSD. Psychiatry Res, 2011; 188: 173-174.

Cao J, Belluzzi JD, Loughlin SE, Dao JM, Chen Y, Leslie FM. Locomotor and stress responses to nicotine differ in adolescent and adult rats. Pharmacol Biochem Behav, 2010; 96: 82-90.

Chiari A, Tobin JR, Pan HL, Hood DD, Eisenach JC. Sex differences in cholinergic analgesia I: a supplemental nicotinic mechanism in normal females. Anesthesiology, 1999; 91: 1447-1454.

Colomer C, Olivos-Oré LA, Vincent A, Mcintosh JM, Artalejo AR, Guérineau NC. Functional characterization of $\alpha 9$-containing cholinergic nicotinic receptors in the rat adrenal medulla: implication in stress-induced functional plasticity. J Neurosci, 2010; 30: 6732-6742.

Dalooei JR, Sahraei H, Meftahi GH, Khosravi M, Bahari Z, Hatef B, et al. Temporary amygdala inhibition reduces stress effects in female mice. J Adv Res, 2016; 7: 643-649.

Dubrovsky BO. Steroids, neuroactive steroids and neurosteroids in psychopathology. Prog Neuropsychopharmacol Biol Psychiatry, 2005; 29: $169-192$.

G Hunter R. Stress and the $\alpha 7$ nicotinic acetylcholine receptor. Current drug targets, 2012; 13: 607-612.

Guérineau NC, Desarménien MG, Carabelli V, Carbone E. Functional chromaffin cell plasticity in response to stress: focus on nicotinic, gap junction, and voltage-gated $\mathrm{Ca} 2+$ channels. Journal of Molecular Neuroscience, 2012; 48: 368-386.

Hunter RG, Bloss EB, Mccarthy KJ, Mcewen BS. Regulation of the nicotinic receptor alpha7 subunit by chronic stress and corticosteroids. Brain Res, 2010; 1325: 141-146.

Javadpour A, Mohammadi A. Implementing a Smart Method to Eliminate Artifacts of Vital Signals. J Biomed Phys Eng, 2015; 5: 199.

Javadpour A, Mohammadi A. Improving Brain Magnetic Resonance Image (MRI) Segmentation via a Novel Algorithm based on Genetic and Regional Growth. J Biomed Phys Eng, 2016; 6:

Le Novere N, Changeux J-P. Molecular evolution of the nicotinic acetylcholine receptor: an example of multigene family in excitable cells. J Mol Evol, 1995; 40: 155-172.
Leão RM, Cruz FC, Marin MT, Da Silva Planeta C. Stress induces behavioral sensitization, increases nicotine-seeking behavior and leads to a decrease of CREB in the nucleus accumbens. Pharmacol Biochem Behav, 2012; 101: 434-442.

Lutfy K, Aimiuwu O, Mangubat M, Shin CS, Nerio N, Gomez $\mathrm{R}$, et al. Nicotine stimulates secretion of corticosterone via both CRH and AVP receptors. J Neurochem, 2012; 120: 1108-1116.

Mcewen BS. Physiology and neurobiology of stress and adaptation: central role of the brain. Physiol Rev, 2007; 87: 873-904.

Mcewen BS. Protective and damaging effects of stress mediators. N Engl J Med, 1998; 338: 171-179.

Miller DB, O'callaghan JP. Neuroendocrine aspects of the response to stress. Metabolism, 2002; 51: 5-10.

Mohammadi A, Hesami E, Kargar M, Shams J. Detecting allocentric and egocentric navigation deficits in patients with schizophrenia and bipolar disorder using virtual reality Neuropsychological Rehabilitation, 2017; 1-18. doi 10.1080/09602011.2017.1369888 (In press).

Müller MB, Keck ME, Zimmermann S, Holsboer F, Wurst W. Disruption of feeding behavior in CRH receptor I-deficient mice is dependent on glucocorticoids. Neuroreport, 2000; 11: 1963-1966.

Myers EA, Rinaman L. Viscerosensory activation of noradrenergic inputs to the amygdala in rats. Physiol Behav, 2002; 77: 723-729.

Niehaus JL, Murali M, Kauer JA. Drugs of abuse and stress impair LTP at inhibitory synapses in the ventral tegmental area. Eur J Neurosci, 2010; 32: 108-117.

Noori-Daloii M, Shahbazi A, Alizadeh Zendehrood S, Shayan Nia A, Mojarrad M, Kheirollahi M, et al. Knocking Down the DRD2 by shRNA Expressing Plasmids in the Nucleus Accumbens Prevented the Disrupting Effect of Apomorphine on Prepulse Inhibition in Rat. J Sci I R Iran, 2015; 26: 205-212.

Tilbrook A, Turner A, Clarke I. Effects of stress on reproduction in non-rodent mammals: the role of glucocorticoids and sex differences. Rev Reprod, 2000; 5: 105-113.

Viveros M-P, Marco E-M, Llorente R, Lamota L. The role of the hippocampus in mediating emotional responses to nicotine and cannabinoids: a possible neural substrate for functional interactions. Behav Pharmacol, 2007; 18: 375-389.

Zhao R, Chen H, Sharp BM. Nicotine-induced norepinephrine release in hypothalamic paraventricular nucleus and amygdala is mediated by $\mathrm{N}$-methyl-D-aspartate receptors and nitric oxide in the nucleus tractus solitarius. J Pharmacol Exp Ther, 2007; 320: 837-844.

\section{How to cite this article:}

Malayeri HR, Sahraei H, Alibeik H, Hatef B, Meftahi GH, Mohammadi A. Intra-accumbal and Peripheral administration of nicotine reduces the side-effects of Inescapable Stress. J App Pharm Sci, 2017; 7 (12): 126-132. 